\title{
OPEN
}
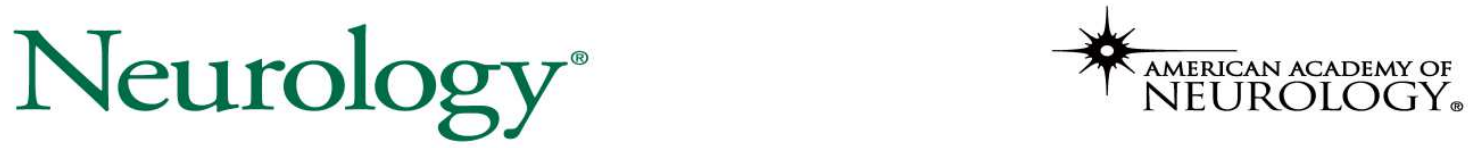

The most widely read and highly cited peer-reviewed neurology journal The Official Journal of the American Academy of Neurology

Neurology Publish Ahead of Print DOI: 10.1212/WNL.0000000000013176

\section{Dermatomyositis: Muscle Pathology According to Antibody Subtypes}

This is an open access article distributed under the terms of the Creative Commons Attribution-NonCommercial-NoDerivatives License 4.0 (CC BY-NC-ND), which permits downloading and sharing the work provided it is properly cited. The work cannot be changed in any way or used commercially without permission from the journal.

Neurology® Published Ahead of Print articles have been peer reviewed and accepted for publication. This manuscript will be published in its final form after copyediting, page composition, and review of proofs. Errors that could affect the content may be corrected during these processes. 
Author(s):

Jantima Tanboon, $\mathrm{MD}^{1,2}$; Michio Inoue, $\mathrm{MD}, \mathrm{PhD}^{1,2}$; Yoshihiko Saito, $\mathrm{MD}, \mathrm{PhD}^{1,2}$; Hisateru Tachimori, $\mathrm{PhD}^{3,4}$; Shinichiro Hayashi, $\mathrm{PhD}^{1,2}$; Satoru Noguchi, $\mathrm{PhD}^{1,2}$; Naoko Okiyama, MD, PhD ${ }^{5}$; Manabu Fujimoto, $\mathrm{MD}, \mathrm{PhD}^{6}$; Ichizo Nishino, $\mathrm{MD}, \mathrm{PhD}^{1,2}$

\section{Corresponding Author:}

Ichizo Nishino

nishino@ncnp.go.jp

Affiliation Information for All Authors: 1. Department of Neuromuscular Research, National Institute of Neuroscience, National Center of Neurology and Psychiatry (NCNP), Tokyo, Japan; 2. Department of Genome Medicine Development, Medical Genome Center, National Center of Neurology and Psychiatry (NCNP), Tokyo, Japan; 3. Department of Clinical Epidemiology, Translational Medical Center, National Center of Neurology and Psychiatry (NCNP), Tokyo, Japan; 4. Endowed Course for Health System Innovation, Keio University School of Medicine, Tokyo, Japan5. Department of Dermatology, Faculty of Medicine, University of Tsukuba, Ibaraki, Japan; 6. Department of Dermatology, Graduate School of Medicine, Osaka University, Osaka, Japan

\section{Contributions:}

Jantima Tanboon: Drafting/revision of the manuscript for content, including medical writing for content; Major role in the acquisition of data; Study concept or design; Analysis or interpretation of data Michio Inoue: Drafting/revision of the manuscript for content, including medical writing for content; Major role in the acquisition of data

Yoshihiko Saito: Drafting/revision of the manuscript for content, including medical writing for content; Major role in the acquisition of data

Hisateru Tachimori: Drafting/revision of the manuscript for content, including medical writing for content Shinichiro Hayashi: Drafting/revision of the manuscript for content, including medical writing for content Satoru Noguchi: Drafting/revision of the manuscript for content, including medical writing for content Naoko Okiyama: Drafting/revision of the manuscript for content, including medical writing for content; Major role in the acquisition of data

Manabu Fujimoto: Drafting/revision of the manuscript for content, including medical writing for content; Major role in the acquisition of data

Ichizo Nishino: Drafting/revision of the manuscript for content, including medical writing for content; Major role in the acquisition of data; Study concept or design; Analysis or interpretation of data

Publication History: This manuscript was pre-published in medRxiv, doi: https://doi.org/10.1101/2021.06.03.21258156

Number of characters in title: 64

Abstract Word count: 348

Word count of main text: 3499

References: 34

Figures: 3

Tables: 4

Supplemental: Revised manuscript with track changes R1 Revised manuscript with track changes R2eTable 1 eTable 2eTable 3 eTable 4eTable 5 eTable 6eFigure 1 eFigure 2eFigure 3 eFigure 4eFigure 5 eFigure 6STROBE 
Statistical Analysis performed by: Jantima Tanboon, MD Department of Neuromuscular Research, National Institute of Neuroscience, National Center of Neurology and Psychiatry (NCNP), Tokyo, JAPANDepartment of Genome Medicine Development, Medical Genome Center, National Center of Neurology and Psychiatry (NCNP), Tokyo, Japan

Search Terms: [ 176 ] All Neuromuscular Disease

Acknowledgements: The authors thank Kazu Iwazawa, Kaoru Tatezawa, Naho Fushimi, Miyuki Matsuda, and Hisayoshi Nakamura for their technical assistance.

Study Funding: This study was supported by Intramural Research Grant 29-4 for Neurologic and Psychiatric Disorders of the National Center of Neurology and Psychiatry.

Disclosures: The authors report no disclosures relevant to the manuscript.
Abstract
Background and Objectives: Discoveries of dermatomyositis specific antibodies (DMSAs) in dermatomyositis patients raised awareness of various myopathological features among antibody subtypes. However, only perifascicular atrophy and perifascicular myxovirus resistant protein $A(M x A)$ overexpression were officially included as the definitive pathological criteria for dermatomyositis classification. We aimed to demonstrate myopathological features in MxA- positive dermatomyositis to determine characteristic myopathological features in different DMSA subtypes.

Method: We performed a retrospective pathology review of muscle biopsies of dermatomyositis patients diagnosed between January 2009 and December 2020 in a tertiary laboratory for muscle diseases. We included all muscle biopsies with sarcoplasmic expression for MxA and seropositivity for DMSAs. MxA-positive muscle biopsies which tested negative for all DMSAs were included as seronegative dermatomyositis. We evaluated histological features 
stratified according to four pathology domains (muscle fiber, inflammatory, vascular, and connective tissue) and histological features of interest by histochemistry, enzyme histochemistry, and immunohistochemical study commonly used in the diagnosis of inflammatory myopathy. We performed ultrastructural studies of 54 available specimens.

Result: A total of 256 patients were included. Of these, 249 patients were positive for one of the five DMSAs (seropositive patients: 87 anti-TIF1-v; 40 anti-Mi-2; 29 anti-MDA5; 83 anti-NXP2; and 10 anti-SAE DM) and 7 patients were negative for all five DMSAs (seronegative patients). Characteristic myopathological features in each DMSA subtype were as follows: anti-TIF1- $\gamma$ with vacuolated/punched out fibers $(64.7 \%, P<.001)$ and perifascicular enhancement in HLA-ABC Stain (75.9\%, $P<.001$ ); anti-Mi-2 with prominent muscle fiber damage (score $4.8 \pm 2.1, P<.001$ ), inflammatory cell infiltration (score $8.0 \pm 3.0, P=.002)$, perifascicular atrophy $(67.5 \%, P=.02)$, perifascicular necrosis $(52.5 \%, P<.001)$, increased perimysial alkaline phosphatase activity (70.0\%, $P<.001)$, central necrotic peripheral regenerating fibers $(45.0 \%, P<.001)$, and sarcolemmal membrane attack complex deposition (67.5\%, $P<.001)$; anti-MDA5 with scattered/diffuse staining pattern of $\operatorname{MxA}(65.5 \%, P<.001)$ with less muscle pathology and inflammatory features; anti-NXP2 with microinfarction $(26.5 \%, P<.001)$; and anti-SAE and seronegative DM with HLA-DR expression (50.0\%, $P=.02$ and $57.1 \%, P=.02$, respectively).

Discussion: We described a comprehensive serological-pathological correlation of DM primarily using MxA expression as an inclusion criterion. In our study, DMSAs were associated with distinctive myopathological features suggesting different underlying pathobiological mechanisms in each subtype. 


\section{Introduction}

The discoveries of dermatomyositis specific antibodies (DMSAs) have transformed the clinically oriented dermatomyositis (DM) classification criteria (primarily based on the presence of skin lesions and muscle weakness described by Bohan and Peter in 1975) to clinic-serologicalpathological criteria proposed by the European Neuromuscular Center (ENMC) in 2018 (2018 ENMC-DM).$^{1-3}$ In the 2018 ENMC-DM consensus, the following 5 DMSAs were included as a serological criteria: anti-transcription intermediary factor $1-\gamma($ TIF1- $-\gamma)$, anti-complex nucleosome remodeling histone deacetylase (Mi-2), anti-melanoma differentiation gene 5 (MDA5), antinuclear matrix protein 2 (NXP-2), and anti-small ubiquitin-like modifier-activating enzyme $(\mathrm{SAE}) .{ }^{2}$ Interestingly, DMSA-associated clinical phenotypes have been characterized, including anti-TIF1- $p$ DM with DM skin lesions, dysphagia, and malignancy; ${ }^{4-6}$ anti-Mi-2 DM with high creatine kinase (CK) level, myalgia, and muscle weakness; ${ }^{7-9}$ anti-MDA5 DM with mechanic hands, and interstitial lung disease (ILD) but low CK levels and less muscle involvement; ${ }^{10,11}$ and anti-NXP-2 DM with muscle weakness but less skin involvement. ${ }^{12,13}$ DMSA-associated pathological phenotypes were also recognized and proposed to be included as "integrated" pathological system for dermatomyositis. ${ }^{14,15}$ However, most of these phenotypes were limited to small studies and were not include in the 2018 ENMC-DM. ${ }^{2,4,7-9,16,17}$ In the 2018 ENMC-DM, only perifascicular atrophy (PFA, the best known pathological feature of DM) and myofiber expression of myxovirus resistant protein $A(M x A$, a surrogate marker for type I interferon pathway activation) were included as definitive pathological criteria. ${ }^{18-21}$ This study aimed to investigate and characterize DMSA-specific pathological features in MxA-positive muscle biopsies. 


\section{Methods}

\section{Patients}

Muscle biopsies from 256 patients pathologically diagnosed with DM at the National Center of Neurology and Psychiatry (NCNP), a nationwide referral center for muscle disease in Japan, from January 2009 to December 2020 were evaluated by confirming the sarcoplasmic MxA expression of neither necrotic nor regenerating muscle fibers. ${ }^{19-21,22}$ Because of the existence of DM sine dermatitis (DMSD), ${ }^{12}$ we regarded all MxA-positive muscle biopsies as DM regardless of the presence of skin lesion. This study was an expansion of the DM cohort from our previous studies ${ }^{7,12}$ and consisted of 249 muscle biopsies from patients positive for one of the 5 DMSAs (seropositive DM) and 7 muscle biopsies from patients who tested negative for all the 5 DMSAs (seronegative DM). We defined patients $<18$ years as juvenile patients.

\section{Serological information}

ELISA for autoantibodies against TIF1- $\gamma$, Mi-2, and MDA5 were covered by the national health insurance system in Japan and were performed according to the manufacturer's instructions (MESACUP ${ }^{T M}$ kit, Medical \& Biological Laboratories Co, Ltd, Nagoya, Japan). Patients testing negative for anti-TIF1- - , Mi-2, and MDA5 antibodies were evaluated by immunoprecipitation and western blotting for autoantibodies against NXP-2 and SAE. ${ }^{23-25}$ 


\section{Histochemical and immunohistochemical evaluation}

Histochemical and immunohistochemical staining for routine diagnostic purposes was performed, including hematoxylin and eosin, modified Gomori trichrome, acid phosphatase (ACP), alkaline phosphatase (ALP), cytochrome C oxidase (COX), Oil Red O, nicotinamide adenine dinucleotide tetrazolium reductase, $\mathrm{MxA}(\mathrm{Mx}$ 1/2/3, Santa Cruz Biotechnology, Dallas, TX, USA), class I human major histocompatibility complex (MHC) (HLA-ABC; clone W6/32, Thermo Fisher Scientific, Waltham, MA, USA), MHC class II (HLA-DR; clone B308, Affinity BioReagents, Golden, CO, USA), membrane attack complex (MAC; C5b-9, clone aE11, Dako, Glostrup, Denmark), neonatal myosin heavy chain (MHCn; clone WB-MHCn, Leica, Wetzlar, Germany), utrophin (clone DRP3/20C65, Leica), CD3 (polyclonal, Abcam, Cambridge, UK), CD8 (clone DK25, Dako), CD20 (clone L26, eBioscience, San Diego, CA, USA), and CD68 (clone KP1, Dako). JT performed pathological evaluation and was blinded to the antibody results at the time of evaluation.

The histochemical and immunohistochemical stained slides, prepared at the time of pathological diagnosis at the NCNP, were evaluated based on 4 domains (muscle fiber, inflammatory, vascular, and connective tissue domains) using the same scoring system as our previous studies modified from the pathology scoring system originally used for juvenile DM (Supplement eTable 1). ${ }^{7,26}$ The scoring system for the muscle fiber domain was based on the presence and extent of necrotic fibers, regenerating fibers, atrophic fibers separated from the perifascicular area, and fibers with internalized nuclei. The inflammatory domain was scoring by CD3-, CD20-, and CD68-positive inflammatory cells in the endomysium and perimysium, and the presence of perivascular inflammatory cell infiltration. The vascular domain scoring was based on the capillary to muscle fiber ratio. The connective tissue domain was scoring based on 
endomysium fibrosis and perimysium pathology, which included fragmentation and alkaline phosphatase expression. ${ }^{6}$ Sarcoplasmic MAC deposition and MHCn expression were used as supporting findings to identify and confirm necrotic and regenerating fibers, respectively. Utrophin was used as a surrogate endothelial marker to evaluate the capillary-to-muscle fiber ratio.

Alongside the PFA, perifascicular necrosis (PFN), decreased COX activity in perifascicular area, perivascular inflammation, vasculitis, CD8 and ACP/CD68 infiltration in non-necrotic fiber, and CD20 aggregation, we included microinfarction, centrally necrotic-and-peripherally regenerating (CNPR) fibers, and vacuolated/punched-out fiber as histopathologies of interest for DM. Microinfarction was defined by the aggregate of at least 3 necrotic fibers without inflammatory cell infiltration into the necrotic fiber accompanied by decreased/absent sarcoplasmic oxidative enzymatic activity on nicotinamide adenine dinucleotide dehydrogenase-tetrazolium reductase. CNPR fibers were defined as fibers presenting necrosis in the central part of the sarcoplasm surrounded by crescent-shaped regenerating portions. Vacuolated/punched out fibers were defined by degenerative non-necrotic fiber with vacuolations. ${ }^{4}$ For MxA staining, 3 patterns were documented: 1) perifascicular pattern if the sarcoplasmic staining limited to the PFA, 2) scattered/diffuse pattern if there was no specific localization, and 3) mixed pattern. The evaluation criteria for histochemical and immunohistochemical staining are described elsewhere. ${ }^{7}$ Ultrastructural evaluation for tubuloreticular inclusions (TRIs) was performed in 54 patients' biopsies. 


\section{Statistical analysis}

We explored histological features by performing multiple correspondence analysis (MCA) followed by agglomerative hierarchical clustering (AHC) using XLSTAT version 2021.2.1 (New Yok, USA, www.XLSTAT.com). For continuous variables, Welch's one-way analysis of variance followed by Dunnett's T3 multiple comparisons test was performed. Welch's t-test and Fisher's exact test were used for continuous and categorial variables to compare findings in one antibody subtype against other antibody subtypes (e.g. anti-TIF1- $ү$ DM vs. non-TIF1- $\vee$ DM); the tests were two-tailed. A $P$-value $<0.05$ was regarded as statistically significant. These analyses were performed using GraphPad Prism version 9.1.0 (216) for Mac OS (GraphPad Software, San Diego, CA, USA).

Standard Protocol Approvals, Registrations, and Patient Consents

This study was approved by the institutional review boards of the NCNP. All clinical information and materials derived from diagnostic testing was permitted for research use with written informed consent from the patients.

\section{Data Availability}

Anonymized data not published within this article will be made available by request from any qualified investigator. 


\section{Results}

\section{Patient Characteristics}

Of the 256 patients pathologically diagnosed with DM by sarcoplasmic MxA expression, 249 patients were DMSA-positive (249 seropositive DM: 87 anti-TIF1- $\gamma, 40$ anti-Mi-2, 29 antiMDA5, 83 anti-NXP-2, and 10 anti-SAE DM) and 7 patients were seronegative. Clinical information of DM patients is summarized in Table 1. There were differences in patient ages among DMSA subtypes $(P<.001)$ (Supplement eFigure $1 \mathrm{a}$ ). The patients who tested positive for anti-TIF1- $\gamma$, anti-Mi-2, and anti-SAE antibodies were older than non-TIF1- $\gamma$ DM $(42.3 \pm 26.2$ years old, $P<.001)$, non-Mi-2 DM (45.3 \pm 27.6 years old, $P=.03)$, and non-SAE DM $(45.6 \pm 6.8$ years old, $P<.001)$ patients, respectively. Patients with anti-TIF1- $\gamma$ and anti-Mi-2 DM were younger than patients with anti-SAE DM ( $P=.003$ and $P=.002$, respectively). Patients that were anti-NXP-2 positive and seronegative DM were younger individuals (non-NXP-2 DM 51.8 \pm 24.9 years old, $P<.001$ and seropositive DM $47.4 \pm 26.4$ years old, $P=.007$, respectively). This was reflected by the larger number of juvenile patients with anti-NXP-2 (42.2\% vs. non-NXP-2 18.5\%, $P<.001)$ and seronegative DM ( $85.7 \%$ vs. seropositive $24.5 \%, P=.002)$. Disease duration, the proportion of patients receiving systemic immunotherapy within 6 weeks of the time of muscle biopsy, the sex ratio of the affected patients, and the biopsy site did not significantly differ among DMSA subtypes (Supplement eTable 2). In anti-TIF1- $\gamma$ DM, biopsies obtained from the biceps brachii (42.5\%) were slightly less common than non-TIF1- DM $(52.5 \%, P=.05)$. The serum CK levels differed among DMSA subtypes ( $P<.001$, Supplement eFigure $1 \mathrm{~b}$ ). Anti-Mi-2 DM was associated with higher CK levels (8113.7 \pm 14314.2 vs. non-Mi-2 2758.2 $\pm 5566.7 \mathrm{U} / \mathrm{L}, P=.03)$, while antiMDA5, anti-SAE, and anti-TIF1- $\gamma$ DM were associated with lower CK levels (394.6 \pm 418.9 vs. nonMDA5 4009.3 $\pm 8232.0 \mathrm{U} / \mathrm{L}, P<.001 ; 492.8 \pm 357.0$ vs. non-SAE $3725.0 \pm 7967.2 \mathrm{U} / \mathrm{L}, P<.001 ;$ and 
1881.2 \pm 4414.3 vs. non-TIF1- $\psi 4472.0 \pm 8981.1 \mathrm{U} / \mathrm{L}, P=0.002$, respectively). Anti-TIF1- $\gamma$ DM patients more commonly presented with skin lesions of any kind (97.7\% vs. non-TIF1- $\gamma 87.0 \%$ DM, $P=.006)$ as well as DM specific skin lesions defined by the 2018 ENMC-DM criteria (89.7\% vs. non-TIF1- $\gamma$ 60.4\%, $P<.001)$. Anti-TIF1- $\gamma$ DM was also associated with dysphagia (47.1\% vs. non-TIF1- $\gamma 28.0 \%, P=.003)$ and malignancy (41.4\% vs. non-TIF1- $\gamma 11.2 \%, P<.001$, Supplement eFigure $1 \mathrm{c}$ ). Notably, anti-TIF1- $\gamma$ DM was associated with malignancy in patients below age 40 (10.5\% vs. non-TIF1- $\gamma 0 \%, P=.04)$, the youngest patient was 36 years old. Anti-Mi-2 DM patients more frequently presented with muscle weakness (100\% vs. non-Mi-2 $87.5 \%, P=.01)$. AntiMDA5 DM was associated with mechanic's hands ( $51.7 \%$ vs. non-MDA5 13.2\%, $P<.001)$ and ILD (79.3\% vs. non-MDA5 10.6\%, $P<.001)$, but was less associated with muscle weakness $(69.0 \%$ vs. non-MDA5 92.1\%, $P=.001$ ) and malignancy (3.5\% vs. non-MDA5 23.8\%, $P=.008$ ). Anti-NXP-2 DM was less likely to be associated with skin lesions of any kind (77.1\% vs. non-NXP-2 97.1\%, $P<.001$ ), DM specific skin lesions (44.6\% vs. non-NXP-2 82.7\%, $P<.001$ ), mechanic's hands (3.6\% vs. non-NXP-2 22.3\%, $P<.001)$, ILD (8.4\% vs. non-NXP-2 23.3\%, $P=.004)$, and malignancy ( $8.4 \%$ vs. non-NXP-2 27.8\%, $P<.001)$. Myalgia was more common in anti-NXP-2 DM (84.2\%) than nonNXP-2 DM (61.6\%, P<.001). Skin ulcers were documented in 4 patients, 2 anti-MDA5 (6.9\%) and 2 anti-TIF1- Y DM (2.3\%), but were not distinctively associated with specific antibody subtype. Anti-SAE was not associated with any distinctive clinical feature. Seronegative DM was less associated with typical DM skin lesions (28.6\%) than seropositive DM (71.5\% $P=.03)$.

\section{Ultrastructural Study}

TRIs were observed in all 54 muscle biopsies (17 anti-TIF1- $\psi, 7$ anti-Mi-2, 5 anti-MDA5, 22 anti-NXP-2, 1 anti-SAE, and 2 seronegative DM). 


\section{Histological Features and Clustering}

We performed MCA on 6 antibody subtypes (5 DMSAs and 1 seronegative) and 23 histologic variables by AHC (Supplement eFigure 2, eTable 3, and eTable 4) and considered the principal coordinates of observations as a set of variables for AHC. The AHC algorithm computed dissimilarities of the variables by Euclidean distance and used Ward's method to successively merge variables into clusters with minimal variance. Because there were 6 antibody subtypes, we proposed 6 pathology classes by truncation. Pathological features in anti-Mi-2, anti-MDA5, anti-SAE, and seronegative DM were more distinctive, with $74.4 \%$ of antiMi-2 patients categorized as class $1,72.4 \%$ of anti-mDA5 being class 3 , and $90.0 \%$ and $100 \%$ of anti-SAE and seronegative DM, respectively, being class 6 . The features in anti-TIF1- - and antiNXP-2 DM were more similar (Supplement eTable 5).

\section{Muscle Pathology Re-Evaluation by Histology Domains}

The muscle fiber domain scores and inflammatory domain scores were different among DMSA subtypes $(P<.001)$ (Figure $1 \mathrm{~A}, \mathrm{~B})$. Compared with the other DMSA groups, muscle biopsies from anti-Mi-2 DM showed higher muscle fiber domain scores (4.9 \pm 2.1 vs. non-Mi-2

2.6 $\pm 2.0, P<.001)$ and higher inflammatory domain scores (8.0 \pm 3.0 vs. non-Mi-2 6.3 $\pm 3.3, P=.002)$ (Table 2). Anti-MDA5 DM showed a lower muscle fiber domain score (1.1 \pm 1.6 vs. non-MDA5 $3.2 \pm 2.1, P<.001)$ and a lower inflammatory domain score $(3.7 \pm 2.4$ vs. non-MDA5 6.9 \pm 3.2 , $P<.001)$. In normal children, the capillary-to-muscle fiber ratio (CFR) was lower than the ratio in adults. ${ }^{25}$ Thus, we evaluated the vascular domain in juvenile and adult patients separately. The CFR value in all adult DM $(0.7 \pm 0.3)$ was lower than the value in 12 normal adult muscle biopsies $(1.1 \pm 0.1, P<.001) .{ }^{11}$ The CFR did not significantly differ among DMSA subtypes (Figure $\left.1 \mathrm{C}, \mathrm{D}\right)$. 
Anti-Mi-2 DM was more commonly associated with increased ALP activity in the perimysium (70.0\% vs. non-Mi-2 29.5\%, $P<.001)$.

\section{Histological Features}

The characteristic features of each DM subtype are shown in Table 3, Figure 2, supplement eFigure 3, eFigure 4, and eFigure5 a. Compared with non-TIF1- $\nu$ DM, anti-TIF1- $\gamma$ DM was associated with vacuolated/punched-out fiber (64.7\% vs. non-TIF1- $\gamma 34.3 \%, P<.001)$ (Figure 2 A). Vacuolated/punched-out fibers were associated with anti-TIF1- $\gamma$ DM with malignancy $(74.3 \%$ vs. non-TIF1- $\gamma$ 15.8\%, $P<.001)$. The following features were associated with anti-Mi-2 DM: PFA (67.5\% vs. non-Mi-2 46.3\%, $P=.02)$, PFN (52.5\% vs. non-Mi-2 3.3\%, $P<.001)$ (Figure 2 B), CD8 infiltration in non-necrotic fibers (7.5\% vs. non-Mi-2 0.9\%, $P=.03$ ), ACP/CD68 infiltration in non-necrotic fibers (20.0\% vs. non-Mi-2 2.8\%, $P<.001)$, CD20 aggregation (28.2\% vs. non-Mi-2 13.0\%, $P=.03$ ), and the presence of CNPR (45.0\% vs. non-Mi-2 20.8\%, $P=.002$ ). Anti-MDA5 DM showed less common PFA (24.1\%, vs. non-MDA5 52.9\%, $P=.005)$ (Figure 2C), decreased COX activity in perifascicular areas (17.2\% vs. non-MDA5 50.0\%, $P<.001)$, perivascular inflammatory cell infiltration ( $13.8 \%$ vs. non-MDA5 48.0\%, $P<.001)$, and vacuolated fiber (20.7\% vs. non-MDA5, 47.6\%, P=.009). Anti-NXP2 DM was associated with microinfarction (26.5\% vs. non-NXP-2 9.3\%, $P<.001$ ) (Figure 2D), and this finding was significant for both adult and juvenile patients. While there was a difference between the percentages of microinfarction affecting adults (12.2\%) and juvenile DM patients $(22.4 \%, P=.05)$, the percentage of microinfarctions in adults (20.8\%) and juvenile anti-NXP-2 DM (34.3\%) was not different $(P=.21)$. In our study, anti-SAE DM did not show any distinctive association with the abovementioned items (supplement eFigure 4). Seronegative DM was associated with perivascular 
inflammation ( $85.7 \%$ vs. seropositive $43.0 \%, P=.05$ ) and vasculitis ( $57.1 \%$ vs. seropositive $14.1 \%$, $P=.01)$.

CNPR fibers were commonly present in muscle biopsies with microinfarction $(57.9 \%$ vs. $18.8 \% P<.001)$ and $36.8 \%(14 / 63)$ of CNPR were present in the infarcted region (Figure $2 \mathrm{D}$, supplement eFigure 6).

\section{Immunohistochemical Features of Interest}

All muscle biopsies in this study expressed both MxA and HLA-ABC. MxA expression showed $37.5 \%$ pure perifascicular staining pattern, $25.4 \%$ scattered/diffuse pattern, and $37.1 \%$ mixed pattern (Figure 3, supplement eFigure 4). Pure perifascicular MxA staining was associated with anti-Mi-2 DM (67.5\% vs. non-Mi-2 31.9\%, $P<.001)$, while a pure scattered/diffuse staining pattern was associated with anti-MDA5 DM (65.5\% vs. non-MDA5 $20.3 \%, P<.001)$. HLA-DR positivity and either scattered or perifascicular patterns were associated with anti-SAE $(50.0 \%$ vs. non-SAE $8.9 \%, P=.002)$ and seronegative DM $(42.9 \%$ vs. seropositive $9.6 \%, P=.03)$. Anti TIF1- $\gamma$ and anti-NXP-2 DM were associated with capillary MAC deposition ( $96.6 \%$ vs. non- TIF1- $\gamma 86.4 \%, P=.009$ and $98.8 \%$ vs. non-NXP-2 85.6\%, $P<.001$ ), capillary MAC deposition with perifascicular pattern (74.7\% vs. non- TIF1- $\gamma 57.4 \%, P=.007$ and 78.3\% vs non-NXP-2 56.1\%, P<.001), and distinct capillary MAC deposition in perifascicular areas (71.3\% vs. non- TIF1- $₹ 55.0 \%, P=.02$ and $75.9 \%$ vs. non-NXP-2 53.2\%, $P<.001)$. Distinct capillary MAC deposition in anti-TIF1- $ү$ DM was not associated with malignancy (69.4\% vs. nonmalignancy associated TIF-1-y 72.6\%, $P=0.81$ ). Sarcolemmal MAC deposition of any pattern or with some area showing perifascicular pattern was present in anti-Mi-2 DM (67.5\% vs. non-Mi-2 
19.0\%, $P<.001$ and 50.0\% vs. non-Mi-2 5.6\%, $P<.001$, respectively)(Table 4, supplement eFigure

3, eFigure 4, and eFigure 5b).

Because the features in anti-TIF1- $\gamma$ and anti-NXP-2 DM tended to overlap, we compared the features in both subtypes (Supplement eTable 5). Anti-TIF1- $\gamma$ DM was associated with perifascicular atrophy $(P=.03)$, vacuolated/punched out fiber $(P=.04)$, and HLA-ABC expression with perifascicular enhancement $(P=.05)$. Anti-NXP-2 DM was associated with ALP activity in PFA $(P=.03)$ and microinfarction $(P=.03)$.

\section{Discussion}

This was a comprehensive study on serological-pathological correlations of different DMSA subtypes. The sarcoplasmic MxA expression was used as a diagnostic finding of DM on muscle pathology as it has been proven to be highly sensitive (71-77\%) and specific (98-100\%) for DM. ${ }^{19,20}$ We also confirmed that the presence of MxA expression was more sensitive than PFA for the diagnosis of DM (100\% vs. 49.6\%). ${ }^{19}$ However, as only MxA with perifascicular pattern is mentioned in the 2018 ENMC-DM classification, this may result in underdiagnosing or misclassification of $25.4 \%$ of DM muscle biopsies. We thus propose that sarcoplasmic MxA expression in non-necrotic/regenerating fibers should be regarded as diagnostic of DM, regardless of the pattern of the distribution of MxA-positive fibers. Using MxA expression as a criterion, we identified 7 seronegative DM that warrant further study and have yet-to-beidentified as DMSAs or as truly seronegative.

We regarded DMSD as a form of DM. ${ }^{12}$ Thus, unlike the 2018 ENMC-DM classification, which requires identification of cutaneous DM features either clinically or pathologically, ${ }^{2}$ we included all qualified muscle biopsies in our serological-pathological criteria regardless of the 
cutaneous features. In this extended cohort, ${ }^{12}$ nineteen anti-NXP-2 antibody-positive patients $(19 / 83,22.9 \%)$ presented no skin lesion of any kind at the time of diagnosis and were classified as DMSD. The proportion was comparable with cases recently reported in a separate study $(8 / 76,10.5 \%, P=.06) .^{24}$

In addition to the DMSA-associated clinical phenotypes that are described above, in our cohort, anti-TIF1- $\gamma$ and anti-Mi-2 were associated with adult patients while anti-NXP-2 was associated with juvenile patients. We confirmed that anti-TIF1- $\gamma$ was distinctively associated with malignancy. Presence of anti-TIF- $\gamma$ antibody in individuals below the age of 40 should also warrant malignancy workup. Anti-SAE DM was associated with elderly patients and a low CK level and showed a trend for DM skin lesions, muscle weakness, dysphagia, and concurrent malignancy, albeit not significantly, which may be at least partly due to the limited number of patients in this study. Seronegative DM was associated with juvenile patients with less frequent DM skin lesions.

Due to the retrospective nature of this study, the clinical information was limited. Thus, we cannot exclude the possibility of malignancy-associated myositis- and DM-specific skin lesions that may develop after muscle biopsy diagnosis. This may affect the prevalence in each antibody subtype. The small number of anti-SAE-DM in our study was likely because of the lower prevalence of anti-SAE DM in Japanese populations. ${ }^{23}$

We used MCA and AHC to explore similarities/differences among DMSA subtypes. We proposed to use 6 as a number for AHC truncation because we believe that different DMSA subtypes (5 DMSAs and seronegative DM) are associated with different pathological mechanisms and pathological features. We later identified pathological characteristics of each 
DM subtype classified by DMSAs; some were previously described in smaller studies.

Histological features in anti-Mi-2 DM were compatible with those previously described in immune myopathy with perimysial pathology (IMPP). ${ }^{7,16}$ By comparing each DMSA with other subtypes, anti-Mi-2 was associated with PFA, ${ }^{7,9}$ PFN, $^{7,16}$ PM-ALP, ${ }^{7,16}$ inflammatory features, ${ }^{7-9}$ perifascicular MxA expression, and sarcolemmal MAC expression. ${ }^{7,9,16}$ We confirmed that antiTIF1- $\gamma$ DM was associated with vacuolated fibers, ${ }^{4}$ HLA-ABC expression with perifascicular enhancement, and distinctive capillary MAC deposition. ${ }^{4}$ Further, vacuolated/punched-out fibers were associated with malignancy-associated anti-TIF1- $\gamma$ DM. ${ }^{4}$ However, we could not demonstrate an association between distinctive capillary MAC deposition and malignancy. Although anti-TIF1- $\gamma$ and anti-NXP2 DM were very similar, anti-TIF- $\gamma$ DM has a higher association with PFA and HLA-ABC expression with perifascicular enhancement, features described for DM with vasculopathy (DM-VP). ${ }^{28,29}$

Anti-NXP-2 was associated with microinfarctions, features described in regional ischemic immune myopathy (RIIM). ${ }^{28}$ Although few cases have been reported describing muscle ischemia or clustered necrosis in juvenile anti-NXP-2 DM, ${ }^{16,17}$ we provide evidence that adult and juvenile anti-NXP-2 DM were equally affected by microinfarction. Since the percentage of microinfarctions in adult and juvenile anti-NXP-2 DM were not significantly different, this phenomenon could not simply be explained by different CFRs between the two age groups. In a recent study of inflammatory myopathies, anti-NXP-2 and anti-TIF1- $\gamma$ were categorized as myovascular myopathy because they both showed loss of endomysial capillaries or positive MAC deposition. ${ }^{30}$ In our study, while the percentage of MAC deposition on capillaries in antiNXP-2 DM was virtually equal to the percentage in anti-TIF1- $ү$ DM, the percentages of 
microinfarction in these two entities were significantly different. Thus, microinfarction could not be explained by complement deposition and warrants further study.

CNPR fibers are peculiar necrotic-regenerating fibers, described as rare in muscular dystrophies, ${ }^{31}$ but their presence has never been fully studied. In our experience, CNPR was not observed in 140 muscle biopsies with genetically confirmed muscular dystrophies (Supplement eTable 6), albeit these muscular dystrophies may sometimes show myositis-mimicking pathology. ${ }^{32}$ It appears that crescent-shaped small regenerating fibers are present at the periphery of necrotic fibers although detailed morphological analysis could not be performed as samples were not available for electron microscopy for the patients with CNPR fibers.

In muscular dystrophies and necrotizing myopathies, necrotic fibers are often invaded by macrophages which are believed to clean up the liquefied sarcoplasm while regeneration is initiated in parallel. In our study, CNPR fibers were significantly associated with microinfarction and some of the neighboring fibers contained lipid droplets or cytoplasmic bodies. These findings, together with their hypoxia-inducible factor expression, suggested that they reflect hypoxic injury. Of note, infarcted fibers do not usually accompany macrophage invasion, which may partly explain why CNPR fibers did not undergo phagocytosis. Interestingly, CNPR fibers were more commonly present in anti-Mi-2 DM which was not associated with microinfarction. Further studies are necessary to better understand whether CNPR fibers in anti-Mi-2 are developed through a mechanism different from those in anti-NXP-2 DM. Anti-MDA5 DM was associated with near normal pathology ${ }^{16,17,33}$ and scattered/diffuse MxA positivity, ${ }^{20}$ while antiSAE DM was distinctively associated with HLA-DR expression. Seronegative DM showed a trend toward inflammation and was associated with significant HLA-DR expression. Since HLA-DR 
expression is a marker of the type II interferon, ${ }^{34}$ there may well be more prominent type II interferon activation in these antibody subtypes.

In conclusion, our study demonstrated distinctive myopathological features associated with DMSA subtypes, which may well indicate the presence of different underlying pathobiological mechanisms. Inclusion of these features into classification criteria would not only increase diagnostic yield but also help classify DM subtypes. 
Access to Data Statement JT and IN had full access to all the data in the study and take responsibility for the integrity of the data and the accuracy of the data analysis. 


\section{Supplement-http://links.lww.com/WNL/B691}

\section{References}

1. Bohan A, Peter JB. Polymyositis and dermatomyositis (first of two parts). N Engl J Med. 1975;292(7):344-347;doi:10.1056/NEJM197502132920706.

2. Mammen AL, Allenbach Y, Stenzel W, Benveniste O, ENMC $239^{\text {th }}$ Workshop study Group. 239th ENMC International Workshop: Classification of dermatomyositis, Amsterdam, the Netherlands, 14-16 December 2018. Neuromuscul Disord. 2020;30(1):70-92;doi:10.1016/j.nmd.2019.10.005.

3. Tanboon J, Uruha A, Stenzel W, Nishino I. Where are we moving in the classification of idiopathic inflammatory myopathies? Curr Opin Neurol. 2020;33(5):590603;doi:10.1097/WCO.0000000000000855.

4. Hida A, Yamashita T, Hosono Y, et al. Anti-TIF1- $\gamma$ antibody and cancer-associated myositis: A clinicohistopathologic study. Neurology. 2016;87(3):299308;doi:10.1212/WNL.0000000000002863.

5. Mugii N, Hasegawa M, Matsushita T, et al. Oropharyngeal Dysphagia in Dermatomyositis: Associations with Clinical and Laboratory Features Including Autoantibodies. PLoS One. 2016;11(5):e0154746;doi:10.1371/journal.pone.0154746.

6. Betteridge Z, Tansley S, Shaddick G, et al. Frequency, mutual exclusivity and clinical associations of myositis autoantibodies in a combined European cohort of idiopathic inflammatory myopathy patients. J Autoimmun. 2019;101:4855;doi:10.1016/j.jaut.2019.04.001.

7. Tanboon J, Inoue M, Hirakawa S, et al. Pathologic Features of Anti-Mi-2 Dermatomyositis. Neurology. 2021;96(3):e448e459;doi:10.1212/WNL.0000000000011269. 
8. Pinal-Fernandez I, Mecoli CA, Casal-Dominguez M, et al. More prominent muscle involvement in patients with dermatomyositis with anti-Mi-2 autoantibodies. Neurology. 2019;93(19):e1768-e1777;doi:10.1212/WNL.0000000000008443.

9. Fornaro M, Girolamo F, Cavagna L, et al. Severe muscle damage with myofiber necrosis and macrophage infiltrates characterize anti-Mi-2 positive dermatomyositis. Rheumatology (Oxford). 2021;60(6):2916-2926;doi:10.1093/rheumatology/keaa739.

10. Allenbach Y, Uzunhan Y, Toquet S, et al. Different phenotypes in dermatomyositis associated with anti-MDA5 antibody: Study of 121 cases. Neurology. 2020;95(1):e70e78;doi:10.1212/WNL.0000000000009727.

11. Mamyrova G, Kishi T, Shi M, et al. Anti-MDA5 autoantibodies associated with juvenile dermatomyositis constitute a distinct phenotype in North America. Rheumatology (Oxford). 2021;60(4):1839-1849;doi:10.1093/rheumatology/keaa429.

12. Inoue M, Tanboon J, Hirakawa S, et al. Association of Dermatomyositis Sine Dermatitis and With Anti-Nuclear Matrix Protein 2 Autoantibodies. JAMA Neurol. 2020;77(7):872:877;doi:10.1001/jamaneurol.2020.0673.

13. Albayda J, Pinal-Fernandez I, Huang W, et al. Antinuclear Matrix Protein 2 Autoantibodies and Edema, Muscle Disease, and Malignancy Risk in Dermatomyositis Patients. Arthritis Care Res (Hoboken). 2017;69(11):1771-1776;doi:10.1002/acr.23188.

14. Allenbach Y, Benveniste O, Goebel HH, Stenzel W. Integrated classification of inflammatory myopathies. Neuropathol Appl Neurobiol. 2017;43(1):6281;doi:10.1111/nan.12380.

15. Benveniste O, Goebel HH, Stenzel W. Biomarkers in Inflammatory Myopathies-An Expanded Definition. Front Neurol. 2019;10:554;doi:10.3389/fneur.2019.00554. 
16. Nguyen M, Do V, Yell PC, et al. Distinct tissue injury patterns in juvenile dermatomyositis auto-antibody subgroups. Acta Neuropathol Commun. 2020;8(1):125;doi:10.1186/s40478-020-01007-3.

17. Yasin SA, Schutz PW, Deakin CT, et al. Histological heterogeneity in a large clinical cohort of juvenile idiopathic inflammatory myopathy: analysis by myositis autoantibody and pathological features. Neuropathol Appl Neurobiol. 2019;45(5):495512;doi:10.1111/nan.12528.

18. Greenberg SA, Pinkus JL, Pinkus GS, et al. Interferon-alpha/beta-mediated innate immune mechanisms in dermatomyositis. Ann Neurol. 2005;57(5):664678;doi:10.1002/ana.20464.

19. Uruha A, Nishikawa A, Tsuburaya RS, et al. Sarcoplasmic MxA expression: A valuable marker of dermatomyositis. Neurology. 2017;88(5):493-500; doi:10.1212/WNL.0000000000003568.

20. Uruha A, Allenbach Y, Charuel JL, et al. Diagnostic potential of sarcoplasmic myxovirus resistance protein A expression in subsets of dermatomyositis. Neuropathol Appl Neurobiol. 2019;45(5):513-522;doi:10.1212/WNL.0000000000003568.

21. Soponkanaporn S, Deakin CT, Schutz PW, et al. Expression of myxovirus-resistance protein A: a possible marker of muscle disease activity and autoantibody specificities in juvenile dermatomyositis. Neuropathol Appl Neurobiol. 2019;45(4):410420;doi:10.1111/nan.12498.

22. Inoue M, Tanboon J, Okubo M, et al. Absence of sarcoplasmic myxovirus resistance protein A (MxA) expression in antisynthetase syndrome in a cohort of 194 cases. Neuropathol Appl Neurobiol. 2019;45(5):523-524;doi:10.1111/nan.12551.

23. Fujimoto M, Matsushita T, Hamaguchi Y, et al. Autoantibodies to small ubiquitin-like modifier activating enzymes in Japanese patients with dermatomyositis: comparison with 
a UK Caucasian cohort. Ann Rheum Dis. 2013;72(1):151-153;doi:10.1136/annrheumdis2012-201736.

24. Ichimura Y, Konishi R, Shobo M, et al. Anti-nuclear matrix protein 2 antibody-positive idiopathic inflammatory myopathies represent extensive myositis without dermatomyositis-specific rash. Rheumatology (Oxford). Published online June 21, 2021. doi:10.1093/rheumatology/keab518.

25. Kishi T, Tani Y, Okiyama N, et al. Anti-SAE autoantibody-positive Japanese patient with juvenile dermatomyositis complicated with interstitial lung disease - a case report.

Pediatr Rheumatol Online J. 2021;19(1):34;doi:10.1186/s12969-021-00532-2.

26. Wedderburn LR, Varsani H, Li CK, et al. International consensus on a proposed score system for muscle biopsy evaluation in patients with juvenile dermatomyositis: a tool for potential use in clinical trials. Arthritis Rheum. 2007;57(7):11921201;doi:10.1002/art.23012.

27. Carry MR, Ringel SP, Starcevich JM. Distribution of capillaries in normal and diseased human skeletal muscle. Muscle Nerve. 1986;9(5):445-454;doi:10.1002/mus.880090510.

28. Cai C, Alshehri A, Choksi R, Pestronk A. Regional ischemic immune myopathy: a paraneoplastic dermatomyopathy. J Neuropathol Exp Neurol. 2014;73(12):11261133;doi:10.1097/NEN.0000000000000132.

29. Bucelli RC, Pestronk A. Immune myopathies with perimysial pathology: Clinical and laboratory features. Neurol Neuroimmunol Neuroinflamm. 2018;5(2):e434; doi:10.1212/NXI.0000000000000434.

30. Pestronk A, Choksi R. Pathology Features of Immune and Inflammatory Myopathies, Including a Polymyositis Pattern, Relate Strongly to Serum Autoantibodies. $J$ Neuropathol Exp Neurol. 2021;80(9):812-820;doi: 10.1093/jnen/nlab071. 
31. Dubowitz V, Sewry CA, Oldfors A, eds. Muscle biopsy: a practical approach. $5^{\text {th }}$ ed. Elsevier; 2020.

32. Allenbach Y, Mammen AL, Benveniste O, Stenzel W, Immune-Mediated Necrotizing Myopathies Working Group. 224th ENMC International Workshop: Clinico-seropathological classification of immune-mediated necrotizing myopathies Zandvoort, The Netherlands, 14-16 October 2016. Neuromuscul Disord. 2018;28(1):8799;doi:10.1016/j.nmd.2017.09.016.

33. Allenbach Y, Leroux G, Suárez-Calvet X, et al. Dermatomyositis with or without antimelanoma differentiation-associated gene 5 antibodies: common interferon signature but distinct NOS2 expression. Am J Pathol. 2016;186(3):691700;doi:10.1016/j.ajpath.2015.11.010.

34. Carey BS, Poulton KV, Poles A. Factors affecting HLA expression: A review. Int J Immunogenet. 2019;46(5):307-320;doi:10.1111/iji.12443. 
Tables

Table 1 Clinical Features of all Dermatomyositis Cases in this Study

\begin{tabular}{|c|c|c|c|c|c|c|c|}
\hline & $\begin{array}{l}\text { All DM } \\
(n=256)\end{array}$ & $\begin{array}{l}\text { Anti- } \\
\text { TIF1- } \gamma \\
(n=87)\end{array}$ & $\begin{array}{c}\text { Anti- } \\
\text { Mi-2 } \\
(n=40)\end{array}$ & $\begin{array}{l}\text { Anti- } \\
\text { MDA5 } \\
(n=29)\end{array}$ & $\begin{array}{l}\text { Anti- } \\
\text { NXP-2 } \\
(n=83)\end{array}$ & $\begin{array}{c}\text { Anti- } \\
\text { SAE } \\
(n=10)\end{array}$ & $\begin{array}{c}\text { Sero- } \\
\text { negative } \\
(n=7)\end{array}$ \\
\hline \multicolumn{8}{|l|}{ Clinical features } \\
\hline Age at biopsy, y & $\begin{array}{c}46.5 \pm \\
26.7\end{array}$ & $\begin{array}{l}54.8 \pm \\
25.8^{*}\end{array}$ & $\begin{array}{l}53.2 \pm \\
20.0^{*}\end{array}$ & $\begin{array}{c}42.5 \pm \\
23.7\end{array}$ & $\begin{array}{l}35.6 \pm \\
27.1^{*}\end{array}$ & $\begin{array}{c}70.4 \pm \\
8.1^{*}\end{array}$ & $\begin{array}{l}17.3 \pm \\
19.9^{*}\end{array}$ \\
\hline Juvenile (<18 years) & $67(26.2)$ & $15(17.2)^{*}$ & $3(7.5)^{*}$ & $8(27.6)$ & $35(42.2)^{*}$ & 0 & $6(85.7)^{*}$ \\
\hline Sex, female & $139(54.3)$ & $48(55.2)$ & $18(45.0)$ & $16(55.2)$ & $47(55.6)$ & $7(70.0)$ & $3(42.9)$ \\
\hline CK (U/L) & $\begin{array}{l}3598.2 \pm \\
7834.3^{\mathrm{a}}\end{array}$ & $\begin{array}{l}1881.2 \pm \\
4414.3^{\mathrm{a}, *}\end{array}$ & $\begin{array}{l}8113.7 \pm \\
14314.2^{*}\end{array}$ & $\begin{array}{l}394.6 \pm \\
481.9 *\end{array}$ & $\begin{array}{c}4685.2 \pm \\
7035.0\end{array}$ & $\begin{array}{l}492.8 \pm \\
357.0^{*}\end{array}$ & $\begin{array}{c}3710.4 \pm \\
7248.1\end{array}$ \\
\hline Skin lesions ${ }^{\mathrm{b}}$ & $232(90.6)$ & $85(97.7)^{*}$ & $37(92.5)$ & $29(100.0)$ & $64(77.1)^{*}$ & $10(100.0)$ & $7(100.0)$ \\
\hline DM skin lesion(s) ${ }^{c}$ & $180(70.3)$ & 78 (89.7)* & $29(72.5)$ & $25(86.2)$ & $37(44.6)^{*}$ & $9(90.0)$ & $2(28.6)^{*}$ \\
\hline Mechanic hands & $45(17.6)$ & $16(18.4)$ & $8(20.0)$ & $15(51.7)^{*}$ & $3(3.6)^{*}$ & $3(30.0)$ & 0 \\
\hline Muscle weakness & $229(89.5)$ & $75(86.2)$ & $40(100.0)^{*}$ & $20(69.0)^{*}$ & $79(95.2)^{*}$ & $9(90.0)$ & $6(85.7)$ \\
\hline Myalgia & $175(68.9)^{d}$ & $59(67.8)$ & $23(57.5)$ & $15(53.6)^{\mathrm{a}}$ & $69(84.1)^{a, *}$ & $4(40.0)$ & $5(71.4)$ \\
\hline Dysphagia & $88(34.5)^{a}$ & $41(47.1)^{*}$ & $8(20.5)^{a}$ & $8(27.6)$ & $25(30.1)$ & $6(60.0)$ & 0 \\
\hline Interstitial lung disease & $47(18.4)^{\mathrm{e}}$ & $11(12.6)$ & $3(7.7)^{\mathrm{e}}$ & $23(79.3)^{*}$ & $7(8.4)^{*}$ & $3(30.0)$ & 0 \\
\hline Malignancy & $55(21.5)$ & $36(41.4)^{*}$ & $7(17.5)$ & $1(3.4)^{*}$ & $7(8.4)^{*}$ & $4(40.0)$ & 0 \\
\hline $\begin{array}{l}\text { Malignancy, } \\
\text { age } \leq 40 \text { years }(n=90)\end{array}$ & $\begin{array}{l}2 / 90 \\
(2.2)\end{array}$ & $\begin{array}{c}2 / 19 \\
(10.5)^{*}\end{array}$ & $\begin{array}{l}0 / 10 \\
(0)\end{array}$ & $\begin{array}{c}0 / 11 \\
(0)\end{array}$ & $\begin{array}{c}0 / 44 \\
(0)\end{array}$ & 0 & $\begin{array}{l}0 / 6 \\
(0)\end{array}$ \\
\hline
\end{tabular}

Abbreviations: DM, dermatomyositis; anti-TIF1- $\gamma$, anti-transcription intermediary factor 1-gamma antibody; anti-

Mi-2, anti-complex nucleosome remodeling histone deacetylase antibody; anti-MDA5, anti-melanoma

differentiation-associated gene 5; anti-NXP-2, anti-nuclear matrix protein 2; anti-SAE, anti-small ubiquitin-like

modifier activating enzyme; $\mathrm{CK}$, creatine kinase.

Continuous data are shown as mean $\pm \mathrm{SD}$; categorial data are shown as number (percentage).

${ }^{\mathrm{a}}$ Information was not available for 1 patient

${ }^{\mathrm{b}}$ Any type of skin lesion

${ }^{\mathrm{C} D M}$ skin lesions as defined by the 239th European Neuromuscular Centre workshop: presence of Grotton

sign/papule and/or heliotrope rash

${ }^{d}$ Information was not available for 2 patients

${ }^{*} p<0.05$ (vs. other antibody subtypes, red-higher score/percentage, blue-lower score/percentage) 
Table 2 Evaluation of pathology domains

\begin{tabular}{|c|c|c|c|c|c|c|c|}
\hline & $\begin{array}{l}\text { All DM } \\
(n=256)\end{array}$ & $\begin{array}{l}\text { Anti- } \\
\text { TIF1- } \gamma \\
(n=87)\end{array}$ & $\begin{array}{l}\text { Anti- } \\
\text { Mi-2 } \\
(n=40)\end{array}$ & $\begin{array}{c}\text { Anti- } \\
\text { MDA5 } \\
(n=29)\end{array}$ & $\begin{array}{c}\text { Anti- } \\
\text { NXP-2 } \\
(n=83)\end{array}$ & $\begin{array}{l}\text { Anti- } \\
\text { SAE } \\
(n=10)\end{array}$ & $\begin{array}{c}\text { Sero- } \\
\text { negative } \\
(n=7)\end{array}$ \\
\hline \multicolumn{8}{|l|}{ Muscle fiber domain } \\
\hline Muscle fiber domain score & $2.9 \pm 2.1$ & $2.9 \pm 1.9$ & $4.9 \pm 2.1^{*}$ & $1.1 \pm 1.6^{*}$ & $2.6 \pm 2.0$ & $3.8 \pm 2.2$ & $2.9 \pm 1.2$ \\
\hline Necrotic fiber score & $0.9 \pm 0.9$ & $0.8 \pm 0.8$ & $1.8 \pm 0.5^{*}$ & $0.3 \pm 0.6^{*}$ & $0.9 \pm 0.9$ & $1.0 \pm 0.8$ & $0.4 \pm 0.5^{*}$ \\
\hline Regenerating fiber score & $0.5 \pm 0.5$ & $0.4 \pm 0.5^{*}$ & $0.8 \pm 0.4^{*}$ & $0.2 \pm 0.4^{*}$ & $0.5 \pm 0.5$ & $0.6 \pm 0.5$ & $0.9 \pm 0.4^{*}$ \\
\hline Atrophic fiber score & $0.5 \pm 0.8$ & $0.5 \pm 0.7$ & $0.9 \pm 0.9 *$ & $0.2 \pm 0.6^{*}$ & $0.4 \pm 0.6^{*}$ & $0.7 \pm 0.8$ & $0.3 \pm 0.8$ \\
\hline PFA score & $0.8 \pm 0.9$ & $0.9 \pm 0.9$ & $1.2 \pm 0.9 *$ & $0.3 \pm 0.7^{*}$ & $0.7 \pm 0.9$ & $1.3 \pm 0.9$ & $1.0 \pm 1.0$ \\
\hline $\begin{array}{l}\text { Fiber with internalized nuclei>3\% } \\
\text { score }\end{array}$ & $0.2 \pm 0.4$ & $0.2 \pm 0.4^{*}$ & $0.2 \pm 0.4$ & $0.0 \pm 0.2^{*}$ & $0.1 \pm 0.3$ & $0.2 \pm 0.4$ & $0.3 \pm 0.5$ \\
\hline \multicolumn{8}{|l|}{ Inflammatory domain } \\
\hline Inflammatory domain score & $6.6 \pm 3.3^{a}$ & $6.6 \pm 3.4$ & $8.0 \pm 3.0^{\mathrm{a}, *}$ & $3.7 \pm 2.4^{*}$ & $6.8 \pm 2.9$ & $5.9 \pm 3.3$ & $8.9 \pm 3.8$ \\
\hline Endomysial CD3 infiltration score & $1.0 \pm 0.7^{\mathrm{a}}$ & $1.0 \pm 0.7$ & $1.3 \pm 0.6^{a, *}$ & $0.6 \pm 0.6^{*}$ & $1.0 \pm 0.6$ & $0.9 \pm 0.6$ & $1.6 \pm 0.8$ \\
\hline Perimysial CD3 infiltration score & $0.5 \pm 0.7^{a}$ & $0.6 \pm 0.7$ & $0.7 \pm 0.7^{a}$ & $0.1 \pm 0.4^{*}$ & $0.5 \pm 0.7$ & $0.6 \pm 0.8$ & $1.0 \pm 1.0$ \\
\hline Endomysial CD20 infiltration score & $1.0 \pm 0.8^{a}$ & $1.0 \pm 0.7$ & $1.5 \pm 0.7^{a, *}$ & $0.3 \pm 0.6^{*}$ & $1.0 \pm 0.7$ & $0.6 \pm 0.7$ & $1.1 \pm 1.0$ \\
\hline Perimysial CD20 infiltration score & $0.5 \pm 0.7^{a}$ & $0.6 \pm 0.7$ & $0.6 \pm 0.7^{\mathrm{a}}$ & $0.1 \pm 0.4^{*}$ & $0.5 \pm 0.7$ & $0.4 \pm 0.8$ & $0.9 \pm 0.7$ \\
\hline Endomysial CD68 infiltration score & $1.8 \pm 0.4^{a}$ & $1.8 \pm 0.5$ & $1.9 \pm 0.3^{\mathrm{a}}$ & $1.6 \pm 0.5^{*}$ & $1.8 \pm 0.4$ & $1.8 \pm 0.4$ & $1.9 \pm 0.3$ \\
\hline Perimysial CD68 infiltration score & $1.2 \pm 0.7^{\mathrm{a}}$ & $1.2 \pm 0.8$ & $1.5 \pm 0.6^{\mathrm{a}, *}$ & $0.8 \pm 0.7^{*}$ & $1.3 \pm 0.7$ & $1.4 \pm 0.5$ & $1.6 \pm 0.5$ \\
\hline $\begin{array}{l}\text { Perivascular inflammatory cell } \\
\text { infiltration score }\end{array}$ & $0.4 \pm 0.5$ & $0.5 \pm 0.5$ & $0.5 \pm 0.5$ & $0.1 \pm 0.4^{*}$ & $0.5 \pm 0.5$ & $0.2 \pm 0.4$ & $0.9 \pm 0.4^{*}$ \\
\hline \multicolumn{8}{|l|}{ Vascular domain } \\
\hline Capillary:fiber ratio, adult patient & $0.7 \pm 0.3+$ & $0.7 \pm 0.3+$ & $0.8 \pm 0.3+$ & $0.8 \pm 0.3+$ & $0.7 \pm 0.3+$ & $0.7 \pm 0.3+$ & 0.9 \\
\hline Capillary:fiber ratio, juvenile patient & $0.5 \pm 0.3^{b}$ & $0.5 \pm 0.2^{b}$ & $0.4 \pm 0.1$ & $0.8 \pm 0.4$ & $0.4 \pm 0.2^{*}$ & NA & $0.6 \pm 0.3$ \\
\hline \multicolumn{8}{|l|}{ Connective tissue domain } \\
\hline Perimysium fragmentation & $182(71.9)^{\mathrm{c}}$ & $61(71.8)^{d}$ & $33(84.6)^{b}$ & $11(37.9)^{*}$ & $63(75.9)$ & $7(70.0)$ & $7(100.0)$ \\
\hline Perimysium ALP activity, increased & $92(35.9)$ & $21(24.1)^{*}$ & $28(70.0)^{*}$ & $4(13.8)^{*}$ & $33(39.8)$ & $2(20.0)$ & $4(57.1)$ \\
\hline Endomysial fibrosis & $37(14.6)^{c}$ & $12(14.1)^{d}$ & $9(23.1)^{b}$ & $1(3.4)$ & $10(12.0)$ & $1(10.0)$ & $4(57.1)^{*}$ \\
\hline
\end{tabular}

Abbreviations: DM, dermatomyositis; anti-TIF1- $\gamma$, anti-transcription intermediary factor 1-gamma antibody; anti-

$\mathrm{Mi}-2$, anti-complex nucleosome remodeling histone deacetylase antibody; anti-MDA5, anti-melanoma

differentiation-associated gene 5; anti-NXP-2, anti-nuclear matrix protein 2; anti-SAE, anti-small ubiquitin-like

modifier activating enzyme; PFA, perifascicular atrophy; CD, cluster of differentiation; NA, not available; ALP,

alkaline phosphatase.

Continuous data are shown as mean \pm SD; categorial data are shown as number (percentage).

${ }^{a}$ Not evaluated in 1 patient due to insufficient tissue for additional staining

${ }^{b}$ Not evaluated in 1 patient due to tissue artifacts

${ }^{\mathrm{c}}$ Not evaluated in 3 patients due to tissue artifacts

${ }^{\mathrm{d}}$ Not evaluated in 2 patients due to tissue artifacts

${ }^{*} p<0.05$ vs. other antibody subtypes (red-higher percentage, blue-lower percentage)

$+p<0.05$ vs. normal specimen (red-higher percentage, blue-lower percentage)

Copyright (c) 2021 The Author(s). Published by Wolters Kluwer Health, Inc. on behalf of the American Academy of Neurology. 
Table 3 Histological features of interests

\begin{tabular}{|c|c|c|c|c|c|c|c|}
\hline & $\begin{array}{l}\text { All DM } \\
(n=256)\end{array}$ & $\begin{array}{l}\text { Anti- } \\
\text { TIF1- } \gamma \\
(n=87)\end{array}$ & $\begin{array}{l}\text { Anti- } \\
\text { Mi-2 } \\
(n=40)\end{array}$ & $\begin{array}{c}\text { Anti- } \\
\text { MDA5 } \\
(n=29)\end{array}$ & $\begin{array}{c}\text { Anti- } \\
\text { NXP-2 } \\
(n=83)\end{array}$ & $\begin{array}{l}\text { Anti- } \\
\text { SAE } \\
(n=10)\end{array}$ & $\begin{array}{c}\text { Sero- } \\
\text { negative } \\
(n=7)\end{array}$ \\
\hline \multicolumn{8}{|l|}{ Histologic features of interest } \\
\hline Perifascicular atrophy & $127(49.6)$ & $49(56.3)$ & $27(67.5)^{*}$ & $7(24.1)^{*}$ & $33(39.8)^{*}$ & $7(70.0)$ & $4(57.1)$ \\
\hline Perifascicular necrosis & 28(10.9) & $3(3.4)^{*}$ & $21(52.5)^{*}$ & 0 & $2(2.4)^{*}$ & 0 & $2(28.6)$ \\
\hline $\begin{array}{l}\text { Decreased COX activity in } \\
\text { perifascicular area }\end{array}$ & $118(46.3)^{a}$ & $47(54.7)^{a}$ & $21(52.5)$ & $5(17.2)^{*}$ & $37(44.6)$ & $4(40.0)$ & $4(57.1)$ \\
\hline $\begin{array}{l}\text { Perivascular inflammatory cell } \\
\text { infiltration }\end{array}$ & $113(44.1)$ & $41(47.1)$ & $18(45.0)$ & $4(13.8) *$ & $42(50.6)$ & $2(20.0)$ & $6(85.7)^{*}$ \\
\hline Vasculitis & $39(15.2)$ & $10(11.5)$ & $10(25.0)$ & 0 & $15(18.1)$ & 0 & $4(57.1)^{*}$ \\
\hline CD8 infiltration in non-necrotic fiber & $5(2.0)^{b}$ & $2(2.3)$ & $3(7.7)^{\mathrm{b}, *}$ & 0 & 0 & 0 & 0 \\
\hline $\begin{array}{l}A C P / C D 68 \text { infiltration in non-necrotic } \\
\text { fiber }\end{array}$ & $14(5.5)$ & $4(4.6)$ & $8(20.0)^{*}$ & 0 & $1(1.2)^{*}$ & 0 & $1(14.3)$ \\
\hline CD20 aggregation & $39(15.3)^{b}$ & $10(11.5)$ & $11(28.2)^{\mathrm{b}, *}$ & $1(3.5)$ & $13(15.7)$ & $1(10.0)$ & $3(42.9)$ \\
\hline Microinfarction & $38(14.8)$ & $11(12.6)$ & 0 & $3(10.3)$ & $22(26.5)^{*}$ & $2(20.0)$ & 0 \\
\hline Microinfarction, adult patients & $23(12.2)$ & $10(13.9)$ & 0 & $1(4.8)$ & $10(20.8)^{*}$ & $2(20.0)$ & 0 \\
\hline Microinfarction, juvenile patient & $15(22.4)$ & $1(6.7)$ & 0 & $2(25.0)$ & $12(34.3)^{*}$ & 0 & 0 \\
\hline $\begin{array}{l}\text { Central necrotic -peripheral } \\
\text { regenerating fibers (CNPR) }\end{array}$ & $63(24.6)$ & $21(24.1)$ & $18(45.0)^{*}$ & $3(10.3)$ & $18(21.7)$ & $2(20.0)$ & $1(14.3)$ \\
\hline Vacuolated, "punched out" fiber & $113(44.5)^{c}$ & $55(64.7)^{c, *}$ & $3(7.5)^{*}$ & $6(20.7)^{*}$ & $40(48.2)$ & $7(70.0)$ & $2(28.6)$ \\
\hline
\end{tabular}

Abbreviations: DM, dermatomyositis; anti-TIF1- $\gamma$, anti-transcription intermediary factor 1-gamma antibody; antiMi-2, anti-complex nucleosome remodeling histone deacetylase antibody; anti-MDA5, anti-melanoma differentiation-associated gene 5; anti-NXP-2, anti-nuclear matrix protein 2; anti-SAE, anti-small ubiquitin-like modifier activating enzyme; COX, cytochrome C oxidase; CD, cluster of differentiation; ACP, acid phosphatase Continuous data are shown as mean $\pm \mathrm{SD}$; categorial data are shown as number (percentage).

${ }^{a}$ Not evaluated in 1 patient due to tissue artifacts

${ }^{\mathrm{b}}$ Not evaluated in 1 patient due to insufficient tissue for additional staining

${ }^{c}$ Not evaluated in 2 patients due to tissue artifacts ${ }^{*} p<0.05$ vs. other antibody subtypes (red-higher percentage, blue-lower percentage) $+p<0.05$ vs. normal specimen (red-higher percentage, blue-lower percentage) 
Table 4 Immunohistochemical features of interests

\begin{tabular}{|c|c|c|c|c|c|c|c|}
\hline & $\begin{array}{l}\text { All DM } \\
(n=256)\end{array}$ & $\begin{array}{l}\text { Anti- } \\
\text { TIF1- } \gamma \\
(n=87)\end{array}$ & $\begin{array}{l}\text { Anti- } \\
\text { Mi-2 } \\
(n=40)\end{array}$ & $\begin{array}{c}\text { Anti- } \\
\text { MDA5 } \\
(n=29)\end{array}$ & $\begin{array}{c}\text { Anti- } \\
\text { NXP-2 } \\
(n=83)\end{array}$ & $\begin{array}{l}\text { Anti- } \\
\text { SAE } \\
(n=10)\end{array}$ & $\begin{array}{c}\text { Sero- } \\
\text { negative } \\
\quad(n=7)\end{array}$ \\
\hline \multicolumn{8}{|l|}{ Immunohistochemical features } \\
\hline MXA positivity & $256(100.0)$ & $87(100.0)$ & $40(100.0)$ & $29(100.0)$ & $83(100.0)$ & 10(100.0) & $7(100.0)$ \\
\hline MXA, perifascicular pattern & $96(37.5)$ & $35(40.2)$ & $27(67.5)^{*}$ & $5(17.2)^{*}$ & $23(27.7)$ & $3(30.0)$ & $3(42.9)$ \\
\hline MXA, scattered/diffuse & $65(25.4)$ & $14(16.1)^{*}$ & $5(12.5)^{*}$ & $19(65.5)^{*}$ & $24(28.9)$ & 0 & 3 (42.9) \\
\hline MXA, mixed pattern & $95(37.1)$ & $38(43.7)$ & $8(20.0)^{*}$ & $5(17.2)^{*}$ & $36(43.4)$ & $7(70.0)^{*}$ & $1(14.3)$ \\
\hline HLA-ABC positivity & $256(100.0)$ & $87(100.0)$ & $40(100.0)$ & $29(100.0)$ & $83(100.0)$ & 10(100.0) & $7(100.0)$ \\
\hline $\begin{array}{l}\text { HLA-ABC, perifascicular } \\
\text { enhancement }\end{array}$ & $149(58.2)$ & $66(75.9)^{*}$ & $26(65.0)$ & $5(17.2)^{*}$ & $41(49.4)$ & $8(80)$ & $3(42.9)$ \\
\hline HLA-DR positivity & $46(18.0)$ & $16(18.4)$ & $5(12.5)$ & $1(3.4)^{*}$ & $15(18.1)$ & $5(50.0)^{*}$ & $4(57.1)^{*}$ \\
\hline HLA-DR, perifascicular pattern & $27(10.5)$ & $8(9.2)$ & $1(2.5)$ & 0 & $10(12.0)$ & $5(50.0)^{*}$ & $3(42.9)^{*}$ \\
\hline MAC capillary deposition & $230(89.8)$ & $84(96.6)^{*}$ & $23(57.5)^{*}$ & $25(86.2)$ & $82(98.8)^{*}$ & $10(100)$ & $6(85.7)$ \\
\hline $\begin{array}{l}\text { MAC capillary deposition with } \\
\text { perifascicular pattern }\end{array}$ & $162(63.3)$ & $65(74.7)^{*}$ & $11(27.5)^{*}$ & $7(24.1)^{*}$ & $65(78.3)^{*}$ & $9(90.0)$ & $5(71.4)$ \\
\hline $\begin{array}{l}\text { Distinct MAC capillary deposition in } \\
\text { perifascicular area }\end{array}$ & $155(60.5)$ & $62(71.3)^{*}$ & $8(20.0) *$ & $9(31.0)^{*}$ & $63(75.9)^{*}$ & $8(80.0)$ & $5(71.4)$ \\
\hline MAC sarcolemmal deposition & $68(26.6)$ & $14(16.1)^{*}$ & $27(67.5)^{*}$ & $2(6.9)^{*}$ & $16(19.3)$ & $5(50.0)$ & $4(57.1)$ \\
\hline $\begin{array}{l}\text { MAC sarcolemmal deposition with } \\
\text { perifascicular pattern }\end{array}$ & $32(12.5)$ & $8(9.2)$ & $20(50.0)^{*}$ & 0 & $2(2.4)^{*}$ & $2(20.0)$ & 0 \\
\hline
\end{tabular}

Abbreviations: DM, dermatomyositis; anti-TIF1- $\gamma$, anti-transcription intermediary factor 1-gamma antibody; anti$\mathrm{Mi}-2$, anti-complex nucleosome remodeling histone deacetylase antibody; anti-MDA5, anti-melanoma differentiation-associated gene 5; anti-NXP-2, anti-nuclear matrix protein 2; anti-SAE, anti-small ubiquitin-like modifier activating enzyme; MxA, myxovirus resistant protein $A ; H L A$, human leukocyte antigen; MAC, membrane attack complex

Continuous data are shown as mean \pm SD; categorial data are shown as number (percentage).

$*_{p<0.05}$ vs. other antibody subtypes (red-higher percentage, blue-lower percentage)

$+p<0.05$ vs. normal specimen (red-higher percentage, blue-lower percentage) 


\section{Figure legends}

\section{Figure 1}

\section{Pathology domains among DMSA subtypes}

A. Muscle fiber domain: anti-Mi-2 DM presented a higher muscle fiber domain score than anti-TIF1- $\gamma$, anti-MDA5, anti-NXP-2, and seronegative DM.

B. Inflammatory domain: anti-MDA5 DM was associated with a lower inflammatory domain score than anti-TIF1- $\gamma$, anti-Mi-2, and anti-NXP-2 DM.

C. Vascular domain: adult capillary-myofiber ratio. The ratio in adult DM was lower than controls. The ratio was not distinctively different among DMSA subtypes.

D. Vascular domain: juvenile capillary-myofiber ratio. The ratio in juvenile DM was not different across DMSA subtypes.

Note: bar=mean $\pm S D$, analysis of variance with Dunnette's T3 multiple comparison ${ }^{*} p<0.0332, * * p<0.0021, * * * p<0.0002, * * * * p<0.0001$

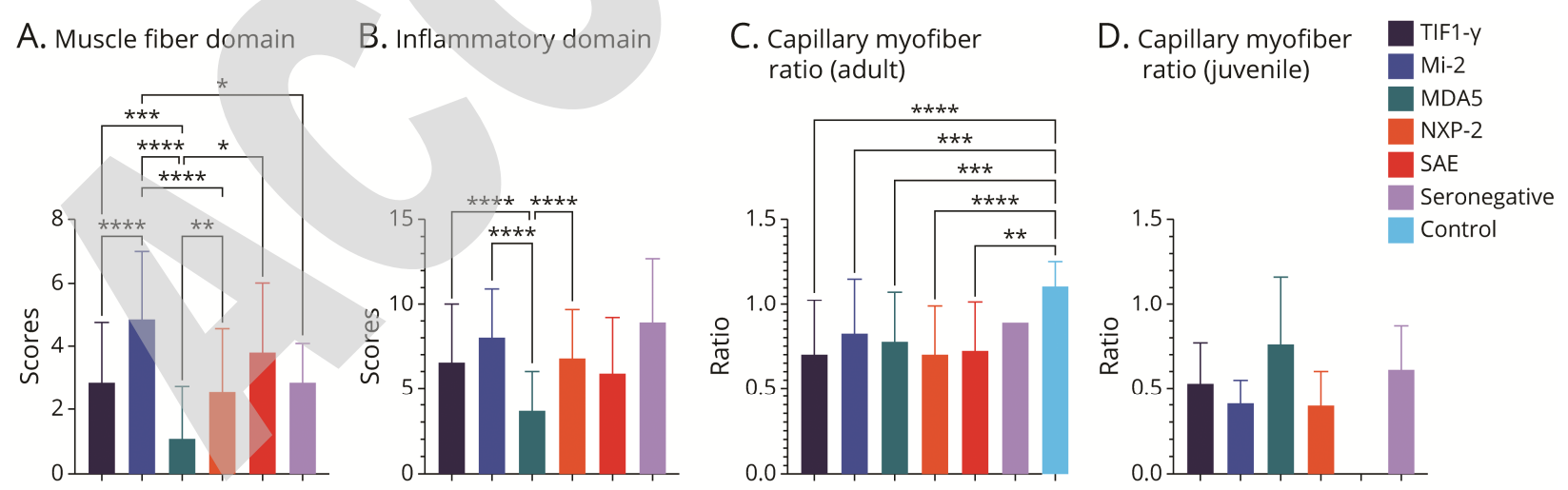




\section{Figure 2}

Pathology features of major DMSA subtypes: On hematoxylin and eosin staining, anti-TIF1- $\gamma$ DM showed perifascicular atrophy with vacuolated/punched-out fibers (A, yellow arrowhead); anti-Mi-2 was associated with perifascicular necrosis (B); anti-MDA5 with near normal appearance (C); and anti-NXP with microinfarction (D, yellow asterisk). central necroticperipheral regenerating fibers (CNPR) were present in anti-Mi-2 and anti-NXP2 subtypes (C and D, yellow arrowhead). bar = 100 microns. DMSA, dermatomyositis specific antibody; DM, dermatomyositis.
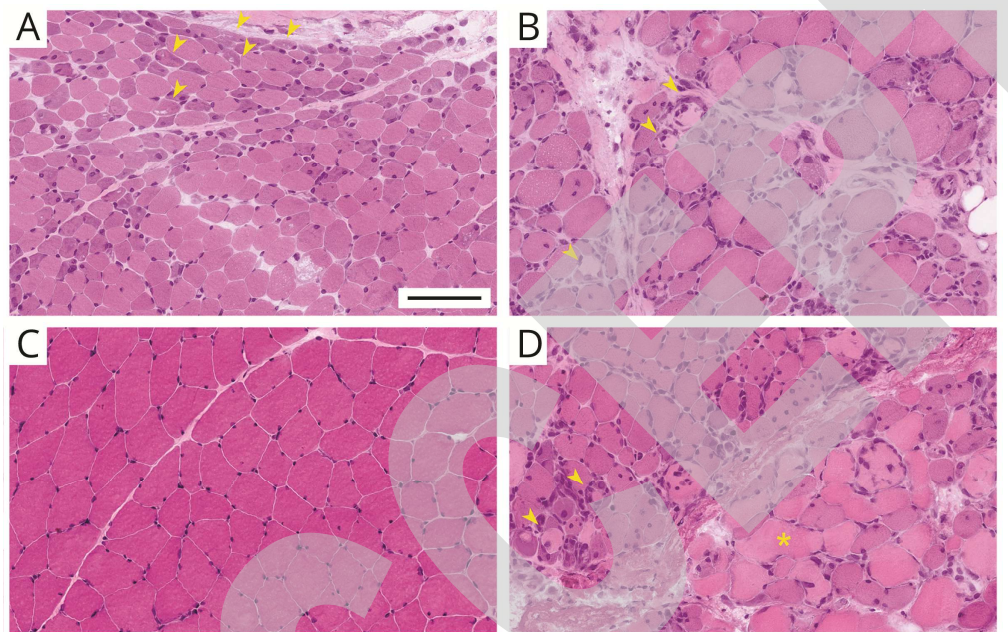


\section{Figure 3}

Myxovirus resistant protein A (MxA) expression patterns in dermatomyositis: Perifascicular pattern ( $A$ and $B)$, and scattered $(C) /$ diffuse $(D)$ pattern. bar = 100 microns
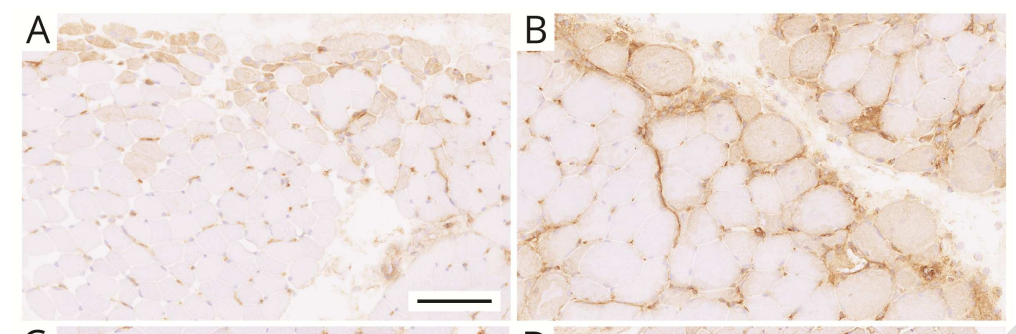

C
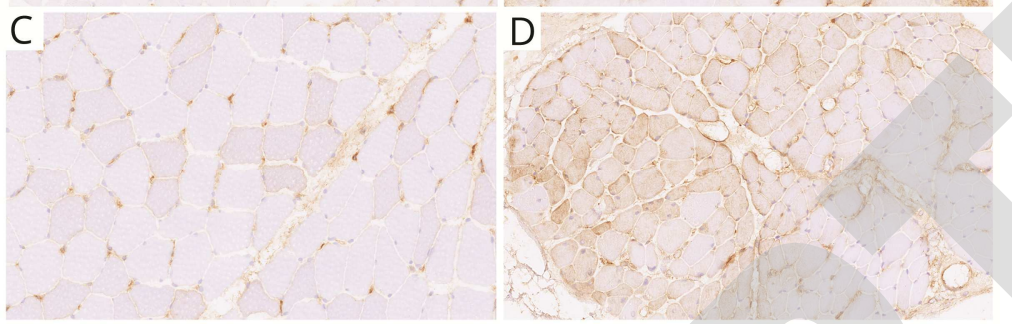


\section{Neurology}

\section{Dermatomyositis: Muscle Pathology According to Antibody Subtypes Jantima Tanboon, Michio Inoue, Yoshihiko Saito, et al. \\ Neurology published online December 6, 2021 \\ DOI 10.1212/WNL.0000000000013176}

This information is current as of December 6, 2021

Updated Information \&

Services

Subspecialty Collections

Permissions \& Licensing

Reprints including high resolution figures, can be found at:

http://n.neurology.org/content/early/2021/12/06/WNL.0000000000013176.f ull

This article, along with others on similar topics, appears in the following collection(s):

All Neuromuscular Disease

http://n.neurology.org/cgi/collection/all_neuromuscular_disease

Information about reproducing this article in parts (figures,tables) or in its entirety can be found online at:

http://www.neurology.org/about/about_the_journal\#permissions

Information about ordering reprints can be found online:

http://n.neurology.org/subscribers/advertise

Neurology $®$ is the official journal of the American Academy of Neurology. Published continuously since 1951, it is now a weekly with 48 issues per year. Copyright Copyright (C) 2021 The Author(s). Published by Wolters

Kluwer Health, Inc. on behalf of the American Academy of Neurology.. All rights reserved. Print ISSN:

0028-3878. Online ISSN: 1526-632X.

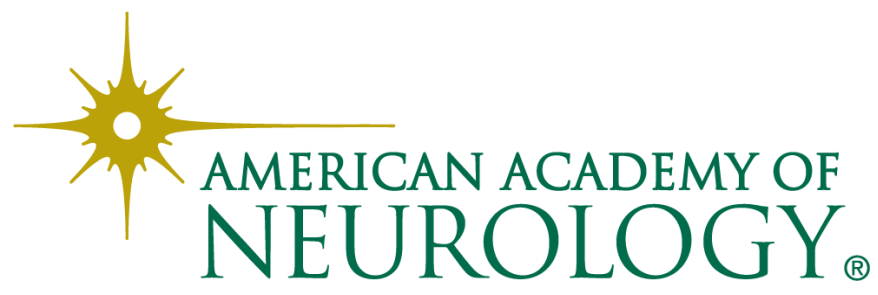

